\title{
DORMÊNCIA E DETERIORAÇÃO DE SEMENTES: UMA REVISÃO
}

\author{
Manoel Victor Borges Pedrosa ${ }^{1}$ \\ Melissa Alvarenga de Oliveira ${ }^{2}$ \\ Alice de Freitas Braga ${ }^{3}$ \\ Nathália Bragança Aparecida Fávaris ${ }^{4}$ \\ Lucimara Ribeiro Venial ${ }^{5}$ \\ Allan Rocha de Freitas ${ }^{6}$ \\ José Carlos Lopes ${ }^{7}$ \\ Rodrigo Sobreira Alexandre ${ }^{8}$
}

Resumo: Objetivou-se realizar um levantamento de trabalhos sobre a dormência e a deterioração de sementes, abordando fatores que induzem a esses processos e apresentando métodos de superação e retardo. Os tipos de dormência em sementes são caracterizadas em dormência fisiológica, endógena ou embrionária, e dormência física, quando é influenciada pelo tegumento. A causa da deterioração acelerada pode ser atribuída a diversos fatores intrínsecos e/ou extrínsecos, sendo este último de maior dificuldade de controle, pois apresenta uma vasta gama de elementos que influenciam nesse processo, como procedimentos de colheita, condições climáticas, modo de secagem, dentre outros. A partir desta revisão é possivel constatar que a dormência pode estar presente em algumas espécies vegetais podendo ser superada através do emprego de alguns métodos de superação, de acordo com a espécie vegetal, e que a deterioração é um processo irreversível, no entanto há meios de promover o retardo.

Palavras-chave: Viabilidade; Escarificação; Armazenamento; Germinação.

\footnotetext{
1 Biólogo, Mestrando em Produção Vegetal, Universidade Federal do Espírito Santo - UFES. Brasil. E-mail: mvborgespedrosa@gmail.com.

2 Graduanda de Engenharia Agronômica, Universidade Federal do Espirito Santo - UFES, Brasil. E-mail: melissalvarengao@gmail.com.

3 Graduanda de Engenharia Agronômica, Universidade Federal do Espirito Santo - UFES, Brasil. E-mail: alicefreitasbraga@hotmail.com.

${ }^{4}$ Graduanda de Engenharia Agronômica, Universidade Federal do Espirito Santo - UFES, Brasil. E-mail: nathbraganca@hotmail.com.

${ }^{5}$ Engenheira Agrônoma, Mestranda em Produção Vegetal, Universidade Federal do Espírito Santo - UFES, Brasil. E-mail: luci_venial@hotmail.com.

${ }^{6}$ Engenheiro Agrônomo, Dr., em Produção Vegetal, Universidade Federal do Espírito Santo - UFES, Brasil. Email: allanrochaf@gmail.com.

${ }^{7}$ Engenheiro Agrônomo, Dr., Professor do Departamento de Produção Vegetal, Centro de Ciências Agrárias, Universidade Federal do Espírito Santo - UFES, Brasil. E-mail: jcufes@bol.com.br.

${ }^{8}$ Engenheiro Agrônomo, Dr., Professor do Departamento de Ciências Florestais e da Madeira, Centro de Ciências Agrárias, Universidade Federal do Espírito Santo - UFES, Brasil. E-mail: rodrigosobreiraalexandre@gmail.com.
} 